Hogness, D. S. \& Mitchell, H. K. (1954). J. gen. Microbiol. 11, 401-411.

\title{
Genetic Factors Influencing the Activity of Tryptophan Desmolase in Neurospora crassa
}

\author{
By D. S. HOGNESS* AND H. K. MITCHELL \\ The Kerckhoff Laboratories of Biology, California Institute of Technology, \\ Pasadena, California, U.S.A.
}

SUMMARY: A simple method for purification of tryptophan desmolase from Neurospora crassa in a good yield is described. No difference could be detected between the tryptophan desmolase extracted from a back-mutated strain of mutant C 83 and that from the wild-type strain. Michaelis constants with respect to the substrates indole and serine and the co-factor pyridoxal phosphate were measured as the basis for possible differences. It is shown that the concentration of tryptophan desmolase in the organism can be determined by genes other than those which induce a tryptophan requirement. Crosses of a histidine-requiring mutant to wild type yielded mutant progeny with 2 to 3 times the normal activity and progeny with no detectable activity under certain conditions. The lack of activity appears to be due to the production of an inhibitor.

Mitchell \& Lein (1948) reported one of the first examples in Neurospora crassa in which the loss of activity of an essential enzyme was directly attributable to a gene mutation. This case concerned a $N$. crassa mutant (C 83) which has an L-tryptophan requirement that cannot be satisfied by indole. The enzyme activity which was lost as a result of this mutation was that of tryptophan desmolase, the enzyme in $N$. crassa which catalyses the synthesis of L-tryptophan from indole and L-serine (Umbreit, Wood \& Gunsalus, 1946; Yanofsky, 1952 a). At a later date it was thought that tryptophan desmolase activity had been found in the $\mathrm{C} 83$ mutant (Gordon \& Mitchell, 1950), but this observation could not be reproduced and has been retracted (Horowitz \& Mitchell, 1951). Yanofsky $(1952 b)$ also reported that he could not detect this enzyme activity in mutant $\mathbf{C} 83$.

The simple picture of the genetic factors responsible for tryptophan desmolase activity in Neurospora crassa has recently been complicated by the findings of Yanofsky (1952b) who reported a mutant, S 1952, which appears to be allelic to mutant $\mathbf{C ~} 83$ and has the same growth requirements and inability to produce detectable amounts of tryptophan desmolase activity. However, when a particular suppressor gene is introduced into strain S 1952, detectable amounts of tryptophan desmolase are produced, whereas the mutant C 83 in combination with the same suppressor gene does not produce detectable amounts of this enzyme.

The present paper deals with two different gene changes in Neurospora crassa which influence the tryptophan desmolase activity. One of these, the back mutation of mutant $\mathrm{C} \mathrm{83}$, fits into the original simple picture, whereas

* Public Health Service Predoctoral Fellow of the National Institutes of Health. Present address : Institut Pasteur, Paris. 
the other, a gene mutation responsible for an L-histidine growth requirement, C 84 (Haas, Mitchell, Ames \& Mitchell, 1952), tends to complicate the picture. It is the purpose of this paper to characterize the changes in tryptophan desmolase activity associated with each of these genetic changes and to analyse their significance.

\section{METHODS}

Crude extracts. Specific activity determinations of tryptophan desmolase in crude extracts were used as a measure of the amount of tryptophan desmolase present in the strains relative to the total amount of protein present. Several wild-type stocks and re-isolates were tested. These and the mutants used were derived from a number of wild stocks (Beadle \& Tatum, 1945). The crude extracts were prepared in the following manner.

The organism was grown at $25^{\circ}$ in $125 \mathrm{ml}$. flasks containing $20 \mathrm{ml}$. minimal medium (Beadle \& Tatum, 1945) supplemented with the appropriate growth factor. At the desired time, the mycelial pads were removed and washed once with distilled water. One g., wet weight, of mycelium was ground for $5 \mathrm{~min}$. in a mortar $(13 \mathrm{~cm}$. in diameter and $7 \mathrm{~cm}$. high) containing $0.5 \mathrm{~g}$. sand, $2 \mathrm{ml}$. $0 \cdot 2 \mathrm{M}-\mathrm{K}_{2} \mathrm{HPO}_{4}$ containing $2 \mathrm{mg}$. DL-serine $/ \mathrm{ml}$. (to stabilize the enzyme), and $2 \mathrm{ml} .0 \cdot 2 \mathrm{M}$-potassium phosphate buffer $(\mathrm{pH} 7 \cdot 7)$. The ground material was centrifuged for $20 \mathrm{~min}$. in a Servall centrifuge at $c .5000$ r.p.m. and the supernatant fluid used as the crude extract. No appreciable activity could be found in the centrifuged precipitates and the specific activity of the crude extracts did not change with increased grinding time up to 25 min.

Measurement of tryptophan desmolase activity. Solutions of indole, serine and pyridoxal phosphate were placed in a 6 in. test tube and equilibrated to $37^{\circ}$ in a water-bath. At time $t=0$, the appropriate amount of tryptophan desmolase extract (also equilibrated to $37^{\circ}$ ) was added and the mixture stirred for a few seconds. Samples $(1.0 \mathrm{ml}$.) were removed at convenient intervals and analysed for indole by a modification of the method of Fearon (1944). Thus the $1.0 \mathrm{ml}$. samples were immediately mixed with $5.0 \mathrm{ml}$. of a solution of $1.0 \mathrm{~g}$. xanthydrol/1. glacial acetic acid. The mixture was then heated at $100^{\circ}$ for 30 min., cooled, and the intensity of the colour produced determined with a Klett-Summerson colorimeter equipped with a green filter (transmission range $c .5000-5700 \mathrm{~A}$ ). The initial velocity $\left(v_{0}\right)$ of the reaction was determined from a plot of colorimeter readings versus time; generally four determinations were used for each plot. The specific activity of the extract ( $\mathrm{m} \mu \mathrm{mole} / \mathrm{min} . / \mathrm{mg}$. protein-nitrogen) is this initial velocity multiplied by the dilution factor of the extract in the reaction mixture and divided by the protein-nitrogen content of the extract. Activity determinations which were used as a measure of the amount of tryptophan desmolase present in an extract were determined under the following standard initial conditions: temperature $=37 \cdot 0^{\circ} ; 0.2 \mathrm{~m}$-potassium phosphate buffer ( $\mathrm{pH} 7 \cdot 6) ; 4.2 \times 10^{-4} \mathrm{M}$-indole; $0.17 \mathrm{M}$-DL-serine; $4.8 \times 10^{-5} \mathrm{M}$-calcium pyridoxal phosphate. Under these conditions, the $v_{0}$ is proportional to the concentration of the enzyme, and for a given enzyme concentration, $v_{0}$ does not increase significantly when the concentrations of the 
substrates and pyridoxal phosphate are doubled. DL-Serine was used here in place of L-serine, since the same initial velocities are observed under these conditions whether $0.17 \mathrm{M}$-DL-serine or $0.085 \mathrm{M}-\mathrm{L}$-serine is employed. The protein-nitrogen content of the extracts was determined by micro-Kjeldahl digestion of $5 \%$ trichloroacetic acid precipitates, followed by Nesslerization.

Partial purification of tryptophan desmolase. Large amounts of mycelium were grown at $25^{\circ}$ in 8 or 161 . of minimal medium under forced aeration. After growth for 4 days, the mycelium was removed, washed 3 times with distilled water, and used immediately or stored at $-16^{\circ}$. Fifteen g. mycelium were ground for $10 \mathrm{~min}$. in a mortar containing $7.5 \mathrm{~g}$. sand and $15 \mathrm{ml} .0 \cdot 2 \mathrm{M}-\mathrm{K}_{2} \mathrm{HPO}_{4}$ containing $2 \mathrm{mg}$. DL-serine $/ \mathrm{ml}$. This ground material was centrifuged for $20 \mathrm{~min}$. in a Servall centrifuge at 5000 r.p.m. and the supernatant fluid retained. This crude extract was heated at $54^{\circ}$ for $6 \mathrm{~min}$. and cooled to $0^{\circ}$. This heat treatment stabilized the tryptophan desmolase, yielding a preparation whose first-order inactivation constant at $3^{\circ}$ was one-third that of the untreated preparation. The extract was then centrifuged in a Spinco Model L ultracentrifuge for $45 \mathrm{~min}$. at 40,000 r.p.m. (145,000 $\mathrm{g}$ maximum). The precipitate was discarded and $18.7 \mathrm{~g}$. solid $\left(\mathrm{NH}_{4}\right)_{2} \mathrm{SO}_{4} / 100 \mathrm{ml}$. extract added and the mixture stirred for $40 \mathrm{~min}$. The extract was then centrifuged at 5000 r.p.m. for $20 \mathrm{~min}$. in a Servall centrifuge. The supernatant fluid was discarded and the precipitate washed once with a solution of $19 \cdot 1 \mathrm{~g} \cdot\left(\mathrm{NH}_{4}\right)_{2} \mathrm{SO}_{4} / 100 \mathrm{ml} .0 \cdot 2 \mathrm{M}-$ potassium phosphate buffer ( $\mathrm{pH} 7 \cdot 7$ ), and the precipitate taken up in $0 \cdot 2 \mathrm{M}$ potassium phosphate buffer ( $\mathrm{pH} 7 \cdot 6$ ), to yield the partially purified material. Unless otherwise indicated, all operations were carried out at $0-3^{\circ}$. This purification procedure yielded a clear solution with a specific activity 15-20 times greater than that of the crude extract (e.g. in one experiment, specific activity of crude and partially purified extracts were 19 and $320 \mathrm{~m} \mu \mathrm{mole} /$ $\mathrm{min} . / \mathrm{mg}$. protein-nitrogen, respectively); the average yield was approximately $60 \%$. This procedure gives about the same purification as that of Yanofsky $(1952 a)$, but has the advantage of being simpler and of giving higher yields.

\section{RESULTS}

\section{Tests for tryptophan desmolase in the $C 83$ mutant}

Experiments designed to detect tryptophan desmolase activity in the $\mathrm{C} 83$ mutant were without success. Mixture of the following extracts from C 83 with active wild-type preparations did not alter the activity of the wild-type extracts: washed mycelium, crude extract, dialysed extract, cell debris, extracts purified according to enzyme purification procedure and precipitates resulting from addition of various amounts of $\left(\mathrm{NH}_{4}\right)_{2} \mathrm{SO}_{4}$ to crude extracts. This indicated that no inhibitor was present in the $\mathrm{C} 83$ extracts. Yanofsky $(\mathbf{1 9 5 2 b})$, using similar conditions and methods, was also unable to find any activity in this mutant.

In order to obtain evidence that the tryptophan requirement and the deficiency of tryptophan desmolase in strain $\mathrm{C} 83$ are due to the same gene change, a cross of the mutant $\mathrm{C} 83$ (mating type $\mathrm{A}$ ) to wild type 8 (mating 
type a) was made and asci were dissected. An examination of 19 asci revealed that there was a 1:1 segregation of these two characteristics and that they always appeared together. With one exception, the specific tryptophan desmolase activity of each of the wild-type progeny did not differ significantly from that of the parent strain ( $8 \mathrm{a}$; specific activity $=17)$. This exception concerned one wild-type spore pair which in six separate experiments gave specific activities of $0,0,0,13,17$, and 15 when grown for 4 days in minimal medium containing $5 \times 10^{-4} \mathrm{M}$-L-tryptophan. It has been demonstrated that the anomalous zero specific activities found for this strain result from the fact that when grown in the presence of L-tryptophan (but not in its absence) this strain loses enzyme activity at some time between 3 and 5 days of growth, although it contains normal enzyme activity at earlier stages of growth. This strain is not heterocaryotic with respect to the mutant gene of $\mathbf{C ~} 83$ and thus this effect of L-tryptophan on the enzyme activity cannot be explained by a preferential multiplication of C 83 nuclei over wild-type nuclei. Although a complete genetic analysis of the character has not been made, it is clear that the phenomenon is independent of the $\mathbf{C} 83$ mutation. This does not however exclude the possibility that the influence of L-tryptophan may be operative in the $\mathbf{C} 83$ mutant.

\section{The back mutation of $C 83$}

A triple mutant of C 83, C 102 and the albino 15300 prepared from the single mutants by crossing was employed in the experiments concerning the back mutation of $\mathrm{C} 83$, the $\mathrm{C} 102$ and 15300 mutant characters being used as markers. The C 102 mutant is phenotypically wild type at $25^{\circ}$ but 'colonial' at temperatures above $31^{\circ}$ (Mitchell \& Mitchell, 1952); this has the advantage of making viable conidial counts relatively easy. As was indicated previously, it was impossible to find any evidence for the existence of tryptophan desmolase in the C 83-C 102-15300 strain.

The back mutation of C 83-C 102-15300 was accomplished in the following manner: a glass-wool filtered suspension of $\mathrm{C} \mathrm{83-C} \mathrm{102-15300} \mathrm{macroconidia}$ containing $3 \cdot 1 \times 10^{6}$ viable conidia $/ \mathrm{ml}$. was divided into two equal parts, and one of these was subjected to ultraviolet irradiation from a Model UV-30 American Sterilizer Company sterilizing lamp for $2 \mathrm{~min}$. at a distance of $10 \mathrm{~cm}$. The other half was not irradiated and was used as the control. The irradiated material contained $1.6 \times 10^{6}$ viable conidia/ml., representing a survival of $52 \%$. Thirty $125 \mathrm{ml}$. flasks, each containing $20 \mathrm{ml}$. minimal medium, were then inoculated with $0.1 \mathrm{ml}$. of the irradiated suspension $\left(1.6 \times 10^{5}\right.$ viable conidia/flask) and twenty-eight such flasks were inoculated with $0.1 \mathrm{ml}$. of the control suspension $\left(3.1 \times 10^{5}\right.$ conidia/flask $)$. These flasks were then allowed to stand at $25^{\circ}$ and were observed over a period of 15 days. Twenty-seven of the thirty flasks inoculated with irradiated conidia contained appreciable amounts of mycelium by this time, whereas none of the flasks inoculated with non-irradiated conidia showed any growth. Thus no reversions were noted in a total of $9 \times 10^{7}$ viable conidia not subjected to irradiation, whereas at least one reversion occurred for every $2 \times 10^{5}$ viable conidia 
subjected to irradiation. Subcultures from those flasks in which growth occurred all exhibited the characteristics of the C 102-15300 double mutant and were indistinguishable from wild type in the amount of growth achieved in four days on minimal medium.

That this reversion of C 83 to wild type was indeed of genetic origin was demonstrated in the following manner. A cross of a reverted culture, $\mathrm{C}$ 83re$\mathrm{C} 102-15300 \mathrm{a}$ to $\mathrm{C} 83-\mathrm{C} 102-15300 \mathrm{~A}$ was made, and the resulting progeny were examined for the 3 mutant characters, tryptophan requirement being used in the case of $\mathrm{C} \mathrm{83}$. Considering only one ascus/perithecium, all twenty asci examined carried the albino 15300 and 'colonial' C 102 markers. Nine of these asci gave a spore pattern of 4 tryptophan-independent $\left(\mathrm{T}^{+}\right)$and 4 tryptophan-dependent $\left(\mathrm{T}^{-}\right)$spores, while in the remaining 11 , all 8 spores were $\mathrm{T}^{-}$. An examination of 2402 random spores germinating on minimal agar revealed $614(26 \%)$ which had a wild-type germination pattern and $1788(74 \%)$ which had a germination pattern identical with the $\mathrm{C} 83$ mutant. These results are those expected if one considers that the macroconidia originally irradiated generally contain more than one nucleus, and hence the original reverted cultures would be expected to be heterocaryotic for $\mathrm{T}^{+}$and $\mathrm{T}^{-}$(Giles, 1951). One would thus expect to find both the $4 \mathrm{~T}^{+}: 4 \mathrm{~T}^{-}$and the $8 \mathrm{~T}^{-}$spore patterns in the asci resulting from the above cross, the frequency of each type presumably depending upon the frequency with which the $\mathbf{T}^{+}$and $\mathbf{T}^{-}$nuclei occur in the heterocaryon.

That this genetic reversion to wild type represents a back mutation and not the action of some suppressor gene was demonstrated in the following manner. $A$ cross of wild type $P 1347$ a with $C 83$ re-C 102-15300A, a homocaryotic reverted strain isolated from the progeny of the previous cross, was made and forty asci were dissected. All of these asci had $8 \mathrm{~T}^{+}$spore patterns. Furthermore, in an examination of $\mathbf{8 7 9 1}$ random ascospores, no $\mathrm{T}^{-}$types were found.

The homocaryotic back-mutated strain C 83re-C 102-15300 was compared with the corresponding strain, C 102-15300, for growth and tryptophan desmolase characteristics. The growth-time curves for these two strains when grown on minimal medium or minimal plus $5 \times 10^{-4} \mathrm{M}$-L-tryptophan are given in Fig. 1. The two curves are typically wild type (e.g. strain 8a), and it is apparent that there was no significant difference between the two strains. No specific difference in the tryptophan desmolase from the two strains could be detected. Crude extracts from the two strains were partially purified (see Methods) and the tryptophan desmolase in the two preparations examined. As can be seen from Table 1, no significant differences in the kinetic constants ( $K_{M}$ values) or the $\mathrm{pH}$ optimum exist between the two preparations.

Taken collectively, these data indicate that the allele of the $\mathrm{C} 83$ gene which results from the back mutation of $\mathrm{C} 83$ is the same as the wild-type allele from which $\mathrm{C} 83$ was derived. At present the $\mathrm{C} 83$ mutation must thus be considered as an essentially reversible process which is accompanied by a loss or gain of detectable tryptophan desmolase activity. 


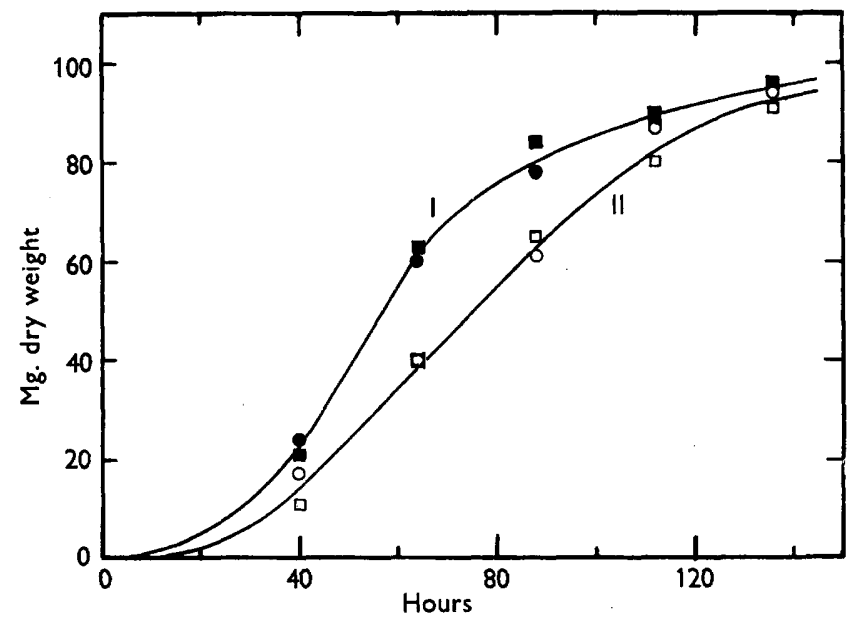

Fig. 1. Growth curves for the back-mutated strain C 83re-C 102-15300 (squares) and strain C $102-15300$ (circles) on minimal medium (I) and on minimal medium $+5 \times 10^{-4}$ M-L-tryptophan (II).

Table 1. Properties of tryptophan desmolase in partially purified extracts from strains $C$ 102-15300 and C 83re-C 102-15300 of Neurospora crassa

\begin{tabular}{lcc} 
Property & \multicolumn{2}{c}{ Strains } \\
\cline { 3 - 3 } C102-15300 & C 83re-C 102-15300 \\
Michaelis constants, $K_{M}{ }^{*}$ & $2 \cdot 3 \times 10^{-5} \mathrm{M}$ & $2 \cdot 8 \times 10^{-5} \mathrm{M}$ \\
Indole & $6 \cdot 3 \times 10^{-3} \mathrm{M}$ & $5 \cdot 7 \times 10^{-3} \mathrm{M}$ \\
L-Serine & $3.4 \times 10^{-6} \mathrm{M}$ & $4 \cdot 4 \times 10^{-6} \mathrm{M}$ \\
Pyridoxal phosphate & $7 \cdot 6$ & $7 \cdot 6$
\end{tabular}

* Determined at $37^{\circ}$ in $0.2 \mathrm{M}$-phosphate buffer (pH 7.6) by Lineweaver-Burk plots (Lineweaver \& Burk, 1934) of the reciprocals of the $v_{0}$ values versus the reciprocals of the initial concentrations, five different concentrations being used for each plot. The accuracy of these $K_{M K}$ values is approximately $\pm 15 \%$. The initial concentrations employed were as follows:

\footnotetext{
$\boldsymbol{K}_{\boldsymbol{M}}$ determined

Indole

L-Serine

Pyridoxal phosphate
}

\begin{tabular}{ccc}
\multicolumn{3}{c}{ Initial concentration (M) } \\
Indole & L-Serine & Pyridoxal phosphate \\
0.47 to $4.7 \times 10^{-4}$ & $8.0 \times 10^{-2}$ & $4.6 \times 10^{-5}$ \\
$4.7 \times 10^{-4}$ & $3.8 \times 10^{-3}$ to $8.0 \times 10^{-2}$ & $4.6 \times 10^{-5}$ \\
$4.7 \times 10^{-4}$ & $8.0 \times 10^{-2}$ & 0.39 to $4.6 \times 10^{-5}$
\end{tabular}

\section{The change in tryptophan desmolase activity attendant on the mutation to $C \mathbf{8 4}$}

The C 84 mutant has an L-histidine requirement that cannot be satisfied by any other compound so far tested and is associated with a single gene (Haas et al. 1952). A comparison of the tryptophan desmolase specific activity in extracts of this strain with that of wild type $8 \mathrm{a}$ when both are grown on minimal medium supplemented with $3 \cdot 2 \times 10^{-4}$ M-histidine is shown in Fig. 2 along with the growth curves of the two strains. The two- to threefold greater specific activity observed in the $\mathrm{C} 84$ extracts after $50 \mathrm{hr}$. of growth apparently 
is not the effect of either an inhibitor in the wild type or an activator in the C 84, since mixtures of the two extracts had activities which were the sum of their individual activities. Furthermore, dialysis of these extracts did not alter their activities.

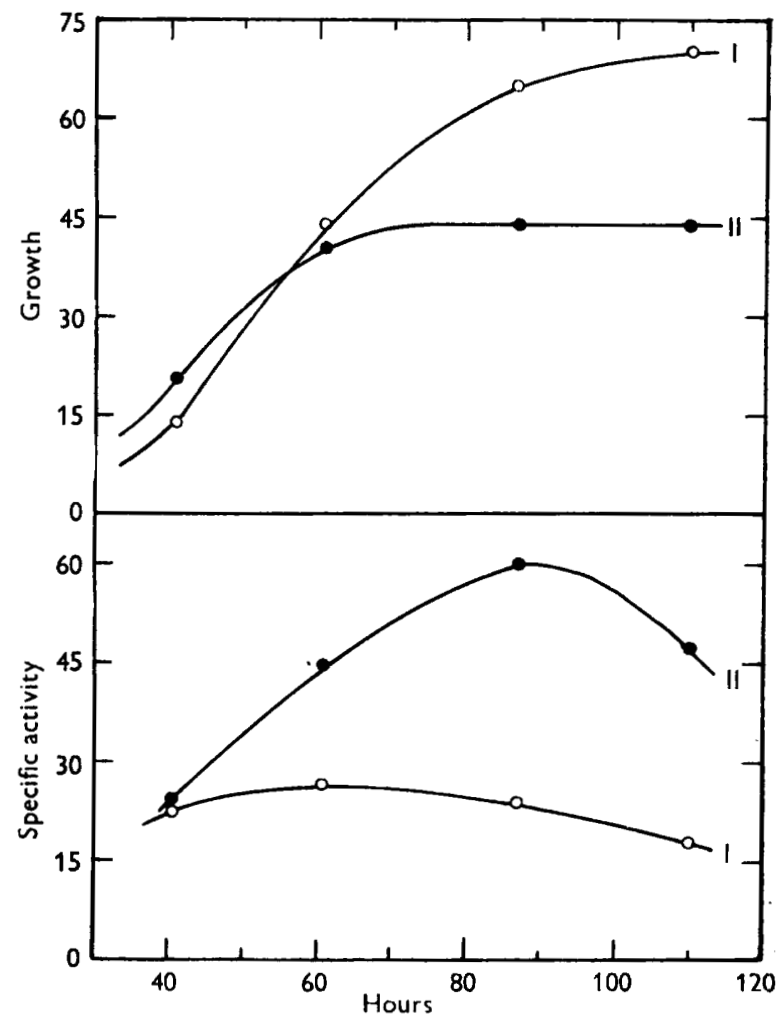

Fig. 2. Growth (mg. dry weight/flask) and specific activity (m $\mu$ mole/min./mg. proteinnitrogen) as a function of time of wild type (I) and mutant C 84, (II). These strains were grown at $25^{\circ}$ in minimal medium $+3 \cdot 2 \times 10^{-4} \mathrm{M}-\mathrm{L}-$ histidine.

In order to determine whether or not the high specific activity of the $\mathbf{C} 84$ strain was directly associated with the histidine requirement of this strain, a cross of $\mathrm{C} 84 \mathrm{~A}$ with wild type $8 \mathrm{a}$ was made and the progeny examined for histidine requirement and tryptophan desmolase activity. The results from the nine asci that were examined are given in Table 2. All of the L-histidineindependent $\left(\mathrm{H}^{+}\right)$strains are seen to possess specific activities which do not differ significantly from the wild-type parent. However, the L-histidinedependent $\left(\mathrm{H}^{-}\right)$strains are seen to possess specific activities which can roughly be classified in two groups: low specific activity, 0-3.7 $\mathrm{m} \mu \mathrm{mole} / \mathrm{min} . / \mathrm{mg}$. protein-nitrogen; high specific activity, 32-60 $\mathrm{m} \mu \mathrm{mole} / \mathrm{min} . / \mathrm{mg}$. proteinnitrogen, which is similar to that of the $\mathrm{C} 84$ strain. Using this classification, the nine asci fall into three groups: (1) five asci with $4 \mathrm{H}^{+}$wild-type activity: $4 \mathrm{H}^{-}$low activity; (2) two with $4 \mathrm{H}^{+}$wild-type activity: $2 \mathrm{H}^{-}$low activity: $2 \mathrm{H}^{-}$high activity; (3) two with $4 \mathrm{H}^{+}$wild-type activity: $4 \mathrm{H}^{-}$high activity. 
Were there a direct association between the histidine requirement and the high activity of the $\mathrm{C} 84$ parent strain, all of the asci would be $4 \mathrm{H}^{+}$, wild-type activity: $4 \mathbf{H}^{-}$, high activity. Thus it is the presence of the $\mathbf{H}^{-}$, low activity progeny which disproves this association.

\section{Table 2. Specific activity of tryptophan desmolase in crude extracts from the parents and progeny of $C 84 A \times 8 a^{*}$}

Parents: Specific activity of $8 a=17$; specific activity of $C 84 A=47$.

Progeny:

Ascus no
1
2
3
4
5
6
7
8
9

Specific activity for spore pairs $\dagger$

$\begin{array}{cccc}\text { H- }^{-} & \text {H- }^{-} & \text {H } & \text { H } \\ 0 \cdot 0 & 2 \cdot 2 & 18 & 19 \\ 0.0 & 1.9 & 16 & 18 \\ 3.7 & 0 \cdot 0 & 19 & 15 \\ 0.0 & 0 \cdot 0 & 17 & 16 \\ 0 \cdot 0 & 0 \cdot 0 & 17 & 16 \\ 0.0 & 43 & 22 & 22 \\ 0 \cdot 0 & 42 & 18 & 16 \\ 33 & 45 & 17 & 22 \\ 35 & 60 & 16 & 17\end{array}$

* The units of specific activity are $\mathrm{m} \mu \mathrm{mole} / \mathrm{min} . / \mathrm{mg}$. protein-nitrogen. The specific activities of the parent strains are the average of 5 independent determinations. Crude extracts were obtained from mycelia grown for 4 days at $25^{\circ}$ in minimal medium $+3.2 \times 10^{-4}$ M-L-histidine.

† The specific activities given in black are the average of the specific activities of the members of the spore pair. There was never any significant difference between the members of a pair. In the other cases only one member of each spore pair was tested.

The $\mathbf{H}^{-}$low activity progeny are all the more remarkable in that, while apparently containing no tryptophan desmolase activity, they grew as well as the $\mathbf{H}^{-}$high activity progeny in the absence of exogenous L-tryptophan, both types of $\mathrm{H}^{-}$progeny having the same growth curve as the $\mathrm{C} \mathrm{84}$ parent. All of these strains, along with the $\mathrm{H}^{-}$high activity and the $\mathrm{H}^{+}$progeny, were therefore examined for tryptophan desmolase activity at various stages of growth; the results are shown in Fig. 3. The wild type and the $\mathbf{H}^{-}$, high activity progeny exhibit the same specific activity-time curves as the wild type $8 \mathrm{a}$ and H-C 84A parents, respectively. The extracts of the $\mathrm{H}^{-}$, high activity and wildtype progeny are also like the extracts from the parent strains in that mixtures of the two have activities which are the sum of their individual activities. Although the activity present in the $\mathbf{H}^{-}$low activity progeny before $50 \mathrm{hr}$. explains how these strains can grow in the absence of exogenous L-tryptophan, it is difficult to imagine that the succeeding fall and rise of specific activity represents a rapid destruction followed by a rapid synthesis of tryptophan desmolase. An inhibitor of tryptophan desmolase catalysis was therefore sought in the extracts which showed low activity.

Experiments which used mixtures of active extracts from wild type 8a and inactive extracts from the $\mathbf{H}^{-}$low activity progeny indicated that an inhibitor was indeed present in the inactive extracts. Thus the representative data in Table 3 show that, as the ratio of inactive extract to active extract is increased, the ratio of the tryptophan desmolase activity observed to that expected if the 
inactive extracts were inert to the tryptophan desmolase system, decreased. This decrease is probably due to an inhibitor and not to destruction of the enzyme, since the activity of the mixed extracts decreased with time at approximately the same rate as that of the active extract alone.

Although it is apparent that the inactive extracts contained a tryptophan desmolase inhibitor, whether or not these extracts contain tryptophan desmolase has not been determined. The rapid rise in activity after $100 \mathrm{hr}$. of growth (Fig. 3) would indicate that they probably do, but a definite answer to this question will have to await the results of investigations as to the nature of this inhibitor.

Table 3. Inhibition of tryptophan desmolase in wild-type extracts by inactive extracts of an $\mathrm{H}^{-}$low activity strain from $\mathrm{C} 84 \mathrm{~A} \times 8$ a cross

\begin{tabular}{|c|c|c|c|c|}
\hline $\begin{array}{l}\text { Fraction wild-type } \\
\text { extract (8a) }\end{array}$ & $\begin{array}{c}\text { Fraction } \\
\text { inactive extract }\end{array}$ & $\begin{array}{l}\text { Observed } \\
\text { activity* }\end{array}$ & $\begin{array}{l}\text { Calculated } \\
\text { activity } \dagger\end{array}$ & $\begin{array}{l}\text { Observed activity } \\
\text { Calculated activity }\end{array}$ \\
\hline $1 \cdot 00$ & 0.00 & $\mathbf{3} \cdot \mathbf{3}$ & $\mathbf{3} \cdot \mathbf{3}$ & $1 \cdot 00$ \\
\hline 0.76 & 0.24 & $2 \cdot 2$ & $2 \cdot 5$ & 0.88 \\
\hline 0.50 & 0.50 & $1 \cdot 0$ & $1 \cdot 6$ & 0.62 \\
\hline 0.24 & 0.76 & $0 \cdot 1$ & 0.8 & $0 \cdot 12$ \\
\hline 0.00 & 1.00 & 0.0 & 0.0 & - \\
\hline
\end{tabular}

* Activity is expressed in $\mathrm{m} \mu \mathrm{mole} / \mathrm{ml} . / \mathrm{min}$.

$\dagger$ Calculated on the assumption that the inactive extract is inert relative to the tryptophan desmolase activity of the wild-type extract.

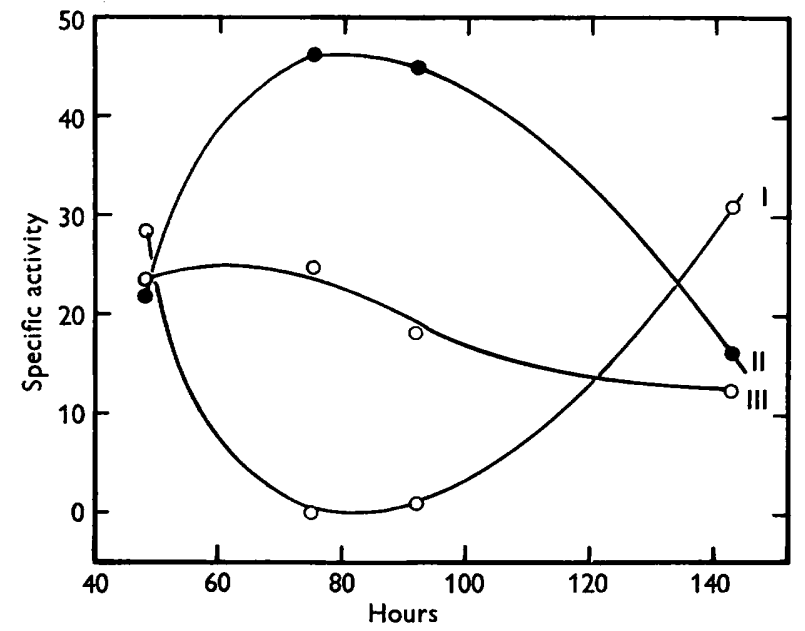

Fig. 3. Specific activity ( $\mathrm{m} \mu \mathrm{mole} / \mathrm{min} . / \mathrm{mg}$. protein-nitrogen) as a function of time of growth of the three types of progeny from $\mathrm{C} 84 \mathrm{~A} \times 8 \mathrm{a}$. I $\mathrm{I}=\mathrm{H}^{-}$, low activity. II $=\mathrm{H}^{-}$, high activity. III $=\mathrm{H}^{+}$(wild type). These strains were grown at $25^{\circ}$ in minimal medium + $3 \cdot 2 \times 10^{-4}$ M-L-histidine.

It is apparent that the data on the cross of $\mathrm{C} 84 \mathrm{~A}$ to $8 \mathrm{a}$ cannot at present be used to evaluate the quantitative effect of the gene responsible for the histidine dependence of $\mathrm{C} \mathrm{84}$ on the actual amount of tryptophan desmolase present in the mould. However, since all the wild-type progeny of this cross have the activity of the wild-type parent, it is very probable that this mutant 
gene (or one closely linked to it) can influence the activity of the enzyme. It is of course possible that one or more specific genes must be present with the C 84 gene in order to alter the activity of tryptophan desmolase, but the uniform parent wild-type activity of the $\mathbf{H}^{+}$progeny would indicate that the other gene or genes could not influence this activity level except in combination with the $\mathrm{C} 84$ gene.

\section{DISCUSSION}

The original observations on mutant C 83 (Mitchell \& Lein, 1948), those by Yanofsky $(1952 a, b)$ and the ones described here are consistent in the demonstration that this mutant does not contain a detectable quantity of tryptophan desmolase when grown under a variety of conditions. These data are in accord with the simple hypothesis that the wild-type allele of the mutant gene of $\mathrm{C} 83$ has a direct function in controlling the synthesis of tryptophan desmolase. However, as shown by the studies on the activity of this enzyme in extracts of the histidine-requiring mutant (C 84) and by the limited information on one wild-type segregant from a C $83 \times$ wild type cross, a number of factors can affect the degree of activity; indeed under certain conditions these strains are very similar to the $\mathrm{C} \mathbf{8 3}$ mutant in that they contain no detectable activity. In this connexion it is of interest to note that L-tryptophan, indole and certain methyl analogues of these compounds inhibit the formation of tryptophan desmolase activity in wild type Aerobacter aerogenes (Cohn \& Monod, 1953). That this effect by tryptophan can exist to some extent, at least in Neurospora crassa, has been shown here and since the strain C 83 will not grow in the absence of tryptophan it is not possible to evaluate the influence of these required growth conditions on the degree of enzyme activity in the mutant. It does seem clear in the case of the low degree of activity in the histidine mutant that an inhibitor of enzyme catalysis is involved, while there is no evidence that this is the case in $\mathbf{C ~ 8 3}$. Nevertheless, an in vivo inhibition of enzyme formation in $\mathrm{C} 83$ is not excluded and available data do not reveal the reasons why this strain is deficient in tryptophan desmolase activity or by what mechanism the wild-type allele is functional in determining the presence of the enzyme activity. Strauss (1953) observed that a $N$. crassa mutant which had a low degree of carboxylase activity had associated with it a low degree of tryptophan desmolase activity.

It is of special interest to note that the tryptophan desmolase derived from a back-mutated strain of $\mathbf{C ~} 83$ was not significantly different from that obtained from the parental strain with respect to the apparent substrate and co-factor Michaelis's constants. Yanofsky (1952b) made similar observations with an enzyme preparation from Neurospora crassa strain S 1952 in which enzyme activity had been restored by action of a suppressor gene. The mutant gene of S 1952 is either allelic with or very closely linked to that of $\mathrm{C} \mathrm{83}$, while the suppressor gene is at a different locus but it does not act to restore tryptophan desmolase activity in strain C 83, as it does in $\mathrm{S} 1952$ (Yanofsky, 1952b). It is clear from these observations that restoration of what appears to be the same enzyme can occur either through back-mutation or by action of an independent 
suppressor gene. Again these results do not distinguish between direct and indirect action of a gene in determining the presence or absence of an active enzyme.

This work was supported in part by funds from the Rockefeller Foundation and by funds from the Atomic Energy Commission administered through contract with the Office of Naval Research, United States Navy, contract No. N-6-onr-244, Task Order 5.

\section{REFERENCES}

Beadle, G. W. \& Tatum, E. L. (1945). Neurospora. II. Methods of producing and detecting mutations concerned with nutritional requirements. Amer. J. Bot. 32, 678.

Conn, M. \& Monod, J. (1953). Adaptation in Micro-organisms. Symp. Soc. gen. Microbiol. 3, 132.

Fearon, W. R. (1944). Detection of indole by means of xanthydrol. Analyst, 69, 122.

Giles, N. H. (1951). Studies on the mechanism of reversion in biochemical mutants of Neurospora crassa. Cold Spr. Harb. Sym. quant. Biol. 16, 283.

Gordon, M. \& Mitchell, H. K. (1950). Tryptophan desmolase in Neurospora. Genetics, 35, 110.

Haas, F., Mitchell, M. B., Ames, B. N. \& Mrtchell, H. K. (1952). A series of histidineless mutants of Neurospora crassa. Genetics, 37, 217.

Horowitz, N. H. \& Mitchell, H. K. (1951). Biochemical genetics. Ann. Rev. Biochem. 20, 477.

Lineweaver, H. \& Burk, D. (1934). The determination of enzyme dissociation constants. J. Amer. chem. Soc. 56, 658.

Mitchell, H. K. \& LeIN, J. (1948). A Neurospora mutant deficient in the enzymatic synthesis of tryptophan. J. biol. Chem. 175, 481.

Mitchell, M. B. \& Mitchell, H. K. (1952). A case of 'Maternal' inheritance in Neurospora crassa. Proc. nat. Acad. Sci., Wash. 38, 442.

Strauss, B. S. (1953). Properties of mutants of Neurospora crassa with low pyruvic carboxylase activity. Arch. Biochem. Biophys. 44, 200.

Umbreit, W. W., Wood, W. A. \& Gunsalus, I. C. (1946). The activity of pyridoxal phosphate in tryptophan formation by cell-free enzyme preparations. $J$. biol. Chem. 165, 731.

Yanofsky, C. (1952a). Tryptophan desmolase of Neurospora. J. biol. Chem. 194, 279.

YANOFSKY, C. $(1952 b)$. The effects of gene change on tryptophan desmolase formation. Proc. nat. Acad. Sci., Wash. 38, 215.

(Received 26 May 1954) 